\title{
Effect of Disposable Sheaths on the Vickers Microhardness of Resin Composites
}

\author{
Meltem Tekbas Atay ${ }^{1}$, Mediha Buyukgoze Dindar ${ }^{2}$, Neslihan Ozveren ${ }^{3}$ \\ ${ }^{1}$ Department of Restorative Dentistry, Faculty of Dentistry, Trakya University, Edirne, Turkey \\ ${ }^{2}$ Health Science Vocational College and Department of Restorative Dentistry, Faculty of Dentistry by Assignment, Trakya University, Edirne, Turkey \\ ${ }^{3}$ Department of Pediatric Dentistry, Faculty of Dentistry, Trakya University, Edirne, Turkey
}

Correspondence Author: Meltem Tekbas Atay

E-mail: meltemtekbas@hotmail.com

Received: $13.06 .2020 \quad$ Accepted: 08.08 .2021

\begin{abstract}
Objective: The aim of this study was to evaluate the effect of disposable sheaths on microhardness of resin composites.

Methods: A total of 40 resin composite specimens were fabricated with disc-shaped perspex molds $(5 \times 2 \mathrm{~mm})$. Specimens were divided into 4 groups: Irradiated by 1-Elipar LCU (EL), 2-Elipar LCU with sheath (ELS), 3-Valo LCU (VL), 4-Valo LCU with sheath (VLS), ( $n=10)$. The specimens were subjected to surface microhardness (SMH) test (Tronic, Digital Microhardness Tester DHV-1000) on the top and bottom surfaces under $200 \mathrm{~g}$ load applied for $10 \mathrm{~s}$ with a Vickers indenter. The specimens were stored in the distilled water at $37{ }^{\circ} \mathrm{C}$ for 24 hours and the same measurements were repeated. One-way ANOVA test, Tukey and Tamhane post-hoc tests were used for intergroup comparisons. Also paired sample t-test was used for comparisons of the different time results.

Results: According to the 1st-hour data from the top and bottom SMH measurements, EL and VL groups have significantly higher microhardness values than VLS and ELS groups $(p<0.05)$. There was a dependent change in the top surface measurements with the time $(p=0.000)$, but also interaction with the LCU ( $p=0.000)$. All groups showed significant microhardness decrease from 1st to 24 th-hour for both top and bottom values $(\mathrm{p}<0.05)$ except for top SMH of VLS group $(\mathrm{p}=0.151)$.

Conclusion: Disposable sheaths decreased the light output of the LCU's and caused reduction in the SMH. Although they are effective in preventing cross-infection, they significantly reduced the polymerization efficiency, thereby mechanical properties of resin composites.

Keywords: Dental Curing Lights, Hardness, Composite Resins
\end{abstract}

\section{INTRODUCTION}

Dental composites are the most commonly used materials in restorative dentistry. With the introduction of light-cured composites, polymerization quality has become the greatest concern of many researchers. Therefore, light-curing units (LCU) have been produced which enable the production of the appropriate amount of light required for efficient conversion of resin composites and to increase their physical and mechanical properties (1). There are four types of polymerization sources currently available; Quartz-tungstenhalogen light-curing units (QTH), plasma arc light devices (PAC), Argon-ion laser and light-emitting diode (LED) (2).

In light-cured composite resins, polymerization is initiated by a photoinitiator that absorbs photons (3). Polymerization occurs when the carbon double bonds in the monomer structure form polymer chains by turning into single bonds. Both physical and chemical properties of composites are directly related to the conversion of monomers into polymers. The greater amount of the polymer means greater resin hardness. Low conversion rates can affect almost every physical property, including resolution, dimensional stability, color change, biocompatibility and it plays an important role in determining the ultimate success of the restoration (4). Additionally, unreacted components may leak from the restoration and lead to cytotoxicity and also may cause microleakage, which can cause caries and pulpal irritation. The minimum light intensity required for proper polymerization is reported to be between 280 and $300 \mathrm{~mW} /$ $\mathrm{cm}^{2}$ for $1.5-2 \mathrm{~mm}$ resin composite (5).

Many variables affect the amount of light absorbed on the top and bottom surfaces of the light-cured composite resin restorations, which can lead to failure of the polymerization. These are; the type of the LCU, diameter of the device tip, distance between the device tip and the restoration surface, power of light, duration of light application, thickness of the resin composite, composition and color of the material (6). Light output can be affected by low voltage, condition of the 
bulb and the filters, the accumulation of resin in the tip of the device and the breaking of the fiber-optic bundles on the LCU. Therefore, regular measurement with a radiometer should be performed.

The Center for Disease Control and Prevention (CDC) refers to tools and equipment that come in contact with the mucose membranes as "semi-critical" and recommends heat or vapor sterilization (7). LCU tips also fall into the "semicritical" instrument category. Therefore; to protect patients and staff when using LCU, high levels of infection control is needed to be performed. Studies have shown that there may be cross-infection during the use of light devices $(8,9)$. Various infection control methods are available for the tips of the light devices, including; disinfectant wipes, autoclavable tips, pre-sterilized disposable plastic sheaths.

The LCU tips can be autoclaved for sterilization, but the procedure can reduce the light output of the device. It was observed that the light intensity of the device could be reduced to $50 \%$ of the original value after 3 times autoclaving of the tip $(10,11)$. If the LCU tips are polished after autoclaving, the light intensity may return to its original value (12). Although polishing can restore light transmission, autoclaving and polishing the tip take time.

Disinfectant solutions such as ethyl alcohol, glutaraldehyde, hypochlorite solutions, iodine-containing solvents, and benzalkonium chloride can be used to clean the LCU tips (6). Some studies have shown that glutaraldehyde-based solutions can reduce light transmission or damage the fiber in the LCU. Also, cold sterilization can be an effective infection control method but requires substantially longer treatment times (10 hours) than autoclaving (13).

Disposable sheaths are a cost-effective method to prevent contamination of the LCU tip. The usage of the plastic sheaths is a non-invasive technique and prevent contact between the oral tissues and the tip. It also eliminates the risk of damage caused by autoclaving or disinfection methods (14). However, several studies have reported that the usage of disposable sheaths significantly reduces the light intensity $(10,15)$. As mentioned before, polymerization quality of the dental composite materials means better physical properties such as high wear resistance or microhardness. Hardness measurement is commonly used to assess the polymerization of composites and consequently the efficiency of the light source (16).

The null hypotheses tested were that (1) there would be no significant difference between the microhardness of polymerized composites when two different LED LCU's were used as uncovered or with a disposable plastic sheath, (2) the surface microhardness (SMH) at the bottom surface of the samples would show lower values than the top surface and (3) after 24 hours, SMH values of all groups would be significantly increased.

\section{METHODS}

The light-cured resin composite used in the present study was Clearfil Majesty Esthetic, shade A2 (Kuraray Medical Inc., Tokyo, Japan). The total inorganic filler ratio of this nanohybrid composite is about $40 \%$ by volume and the particle size of the inorganic fillers ranges from $0.37 \mu \mathrm{m}$ to $1.5 \mu \mathrm{m}$. The composition and application procedure of the material were presented in Table 1.

Table 1. The composite material used in the study.

\begin{tabular}{|c|c|c|c|}
\hline $\begin{array}{l}\text { Material } \\
\text { (Manufacturer) }\end{array}$ & Composition & $\begin{array}{l}\text { Application } \\
\text { Procedure }\end{array}$ & Lot No. \\
\hline $\begin{array}{l}\text { Clearfil Majesty } \\
\text { Esthetic } \\
\text { (Kuraray } \\
\text { Medical Inc., } \\
\text { Tokyo, Japan) }\end{array}$ & $\begin{array}{l}\text { Silanated barium glass } \\
\text { filler ( } 40 \% \text { by volume) } \\
\text { Pre-polymerized organic } \\
\text { filler } \\
\text { Bis-GMA* } \\
\text { Hydrophobic aromatic } \\
\text { dimethacrylate } \\
\text { di-Camphorquinone }\end{array}$ & $\begin{array}{l}\text { Apply in } \\
1-2 \mathrm{~mm} \\
\text { increments } \\
\text { and light } \\
\text { cure for } 20 \mathrm{~s} .\end{array}$ & $4 \mathrm{H} 0158$ \\
\hline
\end{tabular}

*Bis-GMA; Bisphenol A-glycidyl methacrylate

In this study, two different LED light devices were used; Elipar тм DeepCure-S (3M ESPE, St. Paul, MN, USA) and Valo LED (Ultradent Products Inc., South Jordan, UT, USA), (Table 2).

Table 2. Light curing units used in the study.

\begin{tabular}{|c|c|c|c|c|}
\hline $\begin{array}{l}\text { Light } \\
\text { Curing Unit } \\
\text { (Manufacturer) }\end{array}$ & $\begin{array}{l}\text { Curing } \\
\text { Mode }\end{array}$ & Light Intensity & $\begin{array}{c}\text { Emission } \\
\text { Spectrum } \\
\text { (nm) }\end{array}$ & $\begin{array}{l}\text { Stated Tip } \\
\text { Diameter } \\
(\mathrm{mm})\end{array}$ \\
\hline $\begin{array}{l}\text { Elipar }^{\mathrm{TM}} \\
\text { DeepCure-S } \\
\text { (3M ESPE, St, } \\
\text { Paul, MN, USA) }\end{array}$ & $\begin{array}{c}\text { Standard } \\
\text { Power }\end{array}$ & $\begin{array}{c}1.470 \mathrm{~mW} / \mathrm{cm}^{2} \\
(-10 \% /+20 \%)\end{array}$ & $430-480 \mathrm{~nm}$ & 10 \\
\hline $\begin{array}{l}\text { Valo LED } \\
\text { (Ultradent } \\
\text { Products Inc, } \\
\text { South Jordan, } \\
\text { UT, USA) }\end{array}$ & $\begin{array}{c}\text { Standard } \\
\text { Power }\end{array}$ & $\begin{array}{c}1.000 \mathrm{~mW} / \mathrm{cm}^{2} \\
( \pm 10 \%)\end{array}$ & $395-480 \mathrm{~nm}$ & 12 \\
\hline
\end{tabular}

The molds allow a series of resin composite discs to be produced $(5 \mathrm{~mm}$ diameter $\times 2 \mathrm{~mm}$ thickness) that were constructed from perspex. These molds were placed on a flat glass surface and a mylar strip was placed underneath to prevent the resin composite from adhering to the surface.

The resin composite was packed into the mold according to manufacturer's instruction and covered with the mylar strip again to prevent the formation of oxygen inhibition layer in the top layer and then gently pressed with a glass plate to extrude excess material. The light-curing for $20 \mathrm{~s}$ performed according to four groups: 1 - Irradiated by Elipar LCU (EL), 2 - Irradiated by Elipar LCU with sheath (ELS), 3 - Irradiated by Valo LCU (VL), 4 - Irradiated by Valo LCU with sheath (VLS), ( $n=10$ per group).

The disposable sheath used at the second and fourth groups was the disposable hygienic barrier that is available for sale 
with the Valo LED light device. The LCU's tip was positioned in an additional plexiglass jig to standardize the distance and ensure that the tip was directly in the nearest alignment to the top surface of the sample. After polymerization, upper surfaces are marked with an indelible marker pen.

During the use of the LCU's, the power output is measured with a radiometer (SDI LED Radiometer, SDI, Germany) to provide standardization. Also, the Elipar LCU has a test area built into the charger, enables control of the light intensity output. Before each cure, the light intensity output was checked to ensure maximum output. The sheaths were the single-patient use and replaced after each use. While the sheath was placed, it was pulled tight over the tip to ensure that no air was trapped.

The hardness of the specimen was measured at the Vickers hardness tester (Tronic, Digital Microhardness Tester DHV1000) without delay. Each specimen $(n=10)$ was tested on the top and bottom surfaces under a $200 \mathrm{~g}$ load applied for $10 \mathrm{~s}$. Six measurements were recorded on both sides of each sample and averaged for the statistical analysis. The specimens were stored in the distilled water at $37^{\circ} \mathrm{C}$ for 24 hours and the same measurements were repeated.

\section{Statistical Analysis}

The results of microhardness were analyzed by using statistical software, SPSS 22.0 (SPSS Inc., Chicago, IL, USA). The normality of the distributions was confirmed by skewness, kurtosis, and the Kolmogorov-Smirnov test. Besides the descriptive statistics, One-way ANOVA test, Tukey and Tamhane posthoc tests were used for intergroup comparisons. Also paired sample t-test was used for intragroup comparisons of the different time results. All results were considered significant at $p<0.05$.

\section{RESULTS}

The average top and bottom surfaces $\mathrm{SMH}$ values of the samples at the $1^{\text {st }}$ and $24^{\text {th }}$ hours were shown in Table 3. According to the Box's M table, the matrices of covariances were equal $(p=0.447)$.

Table 3. The average top and bottom SMH values of samples at the $1^{\text {st }}$ and $24^{\text {th }}$ hours.

\begin{tabular}{lcccc} 
& $1^{\text {st }} \boldsymbol{h}$ Top SMH & $\mathbf{1}^{\text {st }} \boldsymbol{h}$ Bottom SMH & $\begin{array}{c}\mathbf{2 4}^{\text {th }} \mathbf{h} \text { Top } \\
\mathbf{S M H}\end{array}$ & $\begin{array}{c}\mathbf{2 4}^{\text {th }} \boldsymbol{h} \text { Bottom } \\
\mathbf{S M H}\end{array}$ \\
\hline EL & $30.56 \pm 1.2^{\text {a }}$ & $23.53 \pm 1.0^{\mathrm{a}}$ & $27.67 \pm 0.5^{\mathrm{a}}$ & $22.27 \pm 0.6^{\mathrm{a}}$ \\
ELS & $26.94 \pm 0.6^{\mathrm{b}}$ & $22.03 \pm 0.6^{\mathrm{b}}$ & $25.31 \pm 0.5^{\mathrm{b}}$ & $21.42 \pm 0.4^{\mathrm{b}}$ \\
VL & $31.52 \pm 0.8^{\mathrm{a}}$ & $23.28 \pm 0.8^{\mathrm{a}}$ & $30.12 \pm 0.7^{\mathrm{c}}$ & $21.62 \pm 0.4^{\mathrm{b}}$ \\
VLS & $28.76 \pm 0.6^{\mathrm{c}}$ & $21.22 \pm 0.7^{\mathrm{b}}$ & $29.16 \pm 0.6^{\mathrm{d}}$ & $20.39 \pm 0.5^{\mathrm{c}}$ \\
\hline
\end{tabular}

Different capital letters in the table represent significant differences between groups (columns), ( $p<0.05)$.

In the $1^{\text {st }}$-hour top surface measurements, the highest and lowest SMH values were obtained with the VL and ELS groups, respectively. There was a dependent change in the top surface measurements with the time $(p=0.000)$, but also interaction with the $\mathrm{LCU}(\mathrm{p}=0.000)$. According to the $1^{\text {st }}$-hour data from the top SMH measurements, EL and VL groups presented significantly higher microhardness values than VLS group which also had higher microhardness than ELS group (Table 3).

In the $1^{\text {st }}$-hour bottom surface measurements, the highest and lowest $\mathrm{SMH}$ values were obtained with the EL and VLS groups, respectively. The values of the bottom surface microhardness were decreased with the time $(p=0.000)$ and there was no group interaction due to LCU $(p=0.103)$, (Table 4). EL and VL groups had significantly higher microhardness values than VLS and ELS groups for the bottom SMH measurements $(p=0.000)$.

Table 4. The average percentage of SMH difference between the $1^{\text {st }}$ and $24^{\text {th }}$ hour measurements for the top and bottom surfaces of samples.

\begin{tabular}{lcc} 
Groups & $\begin{array}{c}\mathbf{1}^{\text {st }} \text { to } 24^{\text {th }} \boldsymbol{h} \text { Top SMH } \\
\text { Difference (\%) }\end{array}$ & $\begin{array}{c}\mathbf{1}^{\text {st }} \text { to } 24^{\text {th }} \mathbf{h} \text { Bottom SMH } \\
\text { difference (\%) }\end{array}$ \\
\hline EL & $\% 9.3 \pm 3.7^{\mathrm{a}}$ & $\% 5.2 \pm 5.7^{\mathrm{a}}$ \\
\hline ELS & $\% 6.0 \pm 2.9^{\mathrm{ab}}$ & $\% 2.7 \pm 2.5^{\mathrm{a}}$ \\
\hline VL & $\% 4.4 \pm 2.9^{\mathrm{b}}$ & $\% 7.0 \pm 3.9^{\mathrm{a}}$ \\
\hline VLS & $\% 1.4 \pm 2.9^{\mathrm{c}}$ & $\% 3.8 \pm 4.1^{\mathrm{a}}$ \\
\hline
\end{tabular}

Different capital letters in the table represent significant differences between groups(columns), ( $p<0.05)$.

The average percentage of SMH difference between the top and bottom measurements of the samples at the $1^{\text {st }}$ and $24^{\text {th }}$-hours were shown in Table 5 . For the $1^{\text {st }}$ hour, data percentage of SMH difference between the top and bottom measurements was significantly higher for both Valo groups than ELS group. EL group had a high standard deviation and didn't have a significant difference from other groups $(p>0.05)$.

Table 5. The average percentage of SMH difference between top and bottom measurements of the samples at the $1^{\text {st }}$ and $24^{\text {th }}$ hours.

\begin{tabular}{lcc} 
Groups & $\begin{array}{c}\mathbf{1}^{\text {st }} \mathbf{h} \text { Top-Bottom SMH } \\
\text { Difference (\%) }\end{array}$ & $\begin{array}{c}\mathbf{2 4}^{\text {th }} \mathbf{h} \text { Top-Bottom SMH } \\
\text { Difference (\%) }\end{array}$ \\
\hline EL & $\% 22.9 \pm 4.2^{\mathrm{a}}$ & $\% 19.5 \pm 2.9^{\mathrm{a}}$ \\
ELS & $\% 18.2 \pm 2.7^{\mathrm{ab}}$ & $\% 15.3 \pm 2.6^{\mathrm{b}}$ \\
VL & $\% 26.1 \pm 2.4^{\mathrm{ac}}$ & $\% 28.2 \pm 1.9^{\mathrm{c}}$ \\
VLS & $\% 26.2 \pm 1.4^{\mathrm{ac}}$ & $\% 30.0 \pm 2.3^{\mathrm{c}}$ \\
\hline
\end{tabular}

Different capital letters in the table represent significant differences between groups (columns), $(p<0.05)$.

According to the $24^{\text {th }}$-hour data from the top $\mathrm{SMH}$ measurements, all groups had significant differences from each other. VL group had the highest microhardness values which is followed by VLS, EL and ELS groups, respectively. According to the bottom SMH measurements at the $24^{\text {th }}$ hour, EL group had a significantly higher microhardness values than the other groups. ELS and VL groups showed similar results and also both had significantly higher values than VLS group (Table 3 ). For the $24^{\text {th }}$-hour data percentage of SMH difference between the top and bottom measurements was 
significantly higher for both Valo LCU groups than the both Elipar LCU groups. EL group also had a higher percentage of SMH difference than ELS group (Table 5).

The average percentage of SMH difference between the $1^{\text {st }}$ and $24^{\text {th }}$-hours measurements for the top and bottom surfaces of samples was shown in Table 4. All groups showed significant microhardness decrease from $1^{\text {st }}$ to $24^{\text {th }}$-hour for both top and bottom values $(p<0.05)$ except for top SMH of VLS group which didn't show any significant change between $1^{\text {st }}$ and $24^{\text {th }}$ hours $(p=0.151)$. For the top measurements, $1^{\text {st }}$ to $24^{\text {th }}$-hour difference percentage was significantly higher for EL group than both Valo LCU groups. ELS and VL groups showed similar results which were significantly higher than VLS group. For the bottom measurements, percentage of SMH difference between $1^{\text {st }}$ and $24^{\text {th }}$-hours was similar for all groups.

\section{DISCUSSION}

There are several methods for measuring the degree of conversion of monomers into polymers in the resin composites. These are direct methods such as Laser Raman spectroscopy, Infrared spectroscopy, electron resonance, Fourier Transform Infrared (FTIR) spectroscopy, and indirect methods like scraping and surface hardness test (14). Although the direct microhardness measurement methods are quite time-consuming, difficult and expensive (17), they are the methods that frequently referenced to determine the conversion rates and depth of cure in dental composites, to evaluate the surface hardness and consequently to examine the efficiency of the light source.

Knoop and Vickers are the most commonly used hardness measurement tests. Even though the Knoop hardness test is more frequently used for the evaluation of polymeric materials, such as resin composites because it minimizes the plastic recovery effect (18), several studies have indicated that there is no significant difference between both Knoop and Vickers values (19). Also, the Vickers hardness test which was used at the present study is often preferred because it can predict the degree of polymerization of the resin composites (20).

A square-base diamond pyramid with a $136^{\circ}$ angle between opposite faces is used as the indenter in the Vickers microhardness test (21). In this method, the Vickers hardness values are obtained by measuring the length of the diamond indenter formed on the material under a given load. In microhardness tests, the magnitude of the load has a significant impact on the results. It should be in the range of $1 \mathrm{gf}$ to 1 kgf, commonly 100-500 gf. Indentation with higher load penetrates deeper into the composite, reaches the harder layer and therefore measures greater hardness values (22). The load and duration of the Vickers test have not yet been standardized. Different values were used in various studies. In the present study, the most frequently encountered value of $100 \mathrm{gf}$ and the residence time of $10 \mathrm{~s}$ was applied.
There can be significant changes in the values obtained by the penetration of the intender on the resin matrix or the filler particle during application. Therefore, it is recommended not to take extremely high values into account because they may affect the result (23). Also, when determining the hardness values, at least three measurements should be made from a surface and the average of these values should be taken as a basis.

The studies showed that the content of composite resins, the structure of the resin matrix, the volume and the ratio of inorganic fillers and shade may affect the hardness values of the material $(2,24)$. Resins containing high fillers show high hardness values. Since the effect of the hygienic sheath on polymerization was measured in this study, the same resin composite was used to avoid the differences due to the material.

The standard incremental placement of the resin composite is $2 \mathrm{~mm}$, if the increment placed was slightly over $2 \mathrm{~mm}$, it may lead to incomplete polymerization of the resin and thus poorer mechanical performance (25). Pollington et al. stated that there were no significant differences between the depth of cure of resin composite cured at $0-2 \mathrm{~mm}$. However, as the thickness progressed from $3 \mathrm{~mm}$ to $5 \mathrm{~mm}$, they noted a significant reduction in hardness values (14). For this reason, the molds were produced with a height of $2 \mathrm{~mm}$ according to the manufacturer's instructions for each layer.

If the wavelength of light from the LCU is significantly affected when a sheath is used, the composite can not be fully polymerized. It is reported that the hygienic barrier can reduce the light output by $5-10 \%$ in the Valo manual. On the other hand, studies have shown that light intensity can be reduced by up to $35 \%$ when some plastic sheaths were used $(11,12,14)$. Similarly, according to the result of the present study, the usage of the hygienic sheaths reduced the light output of two LCU's, thereby microhardness of the samples. This is thought to be since the protective sheaths reduce the light output power of the light device (26). Thus, the first null hypothesis was rejected. These findings were consistent with the studies of Warren et al. and Scott et al. $(7,12)$. However, McAndrew et al. (26). were reported that infection control barriers do not significantly reduce power output. Likewise, Pollington et al. were observed no significant difference with or without the use of the sheath. They also reported that the use of the sheaths provided an acceptable depth of cure when used with the $2 \mathrm{~mm}$ increment rule. It was not until 3 $\mathrm{mm}$ that the use of sheaths compromised the performance of the resin composite (14).

When the Valo LCU was used without the sheath, the highest surface hardness results were obtained on the top surface. Even though Elipar LCU had a higher light intensity, on the top surface highest microhardness values withouth sheath were obtained with Valo LCU. This result can be attributed to the unique tip design, beam collimation and uniformity of Valo LCU. Considering the surface microhardness values, there was a significant difference between LCU's, and this 
proves that the type of the LCU can affect the microhardness values (4).

As a result of the present study, higher microhardness values were obtained on the top surfaces than the bottom surfaces (Table 3 ), as in the previous studies $(2,23)$. The second hypothesis was accepted. This is explained by the fact that the light passes through the mass of the restorative material, its density decreases greatly, and therefore reduces its curing potential (4). Also, filler content and particle size of the material play an important role in the degree of polymerization at the bottom surface $(27,28)$.

When the measurements on the top surfaces at the $1^{\text {st }}$ and $24^{\text {th }}$ hours were compared, it was observed that there was a statistically significant difference in time in all groups except VLS group. On the bottom surface, there was a significant difference between the $1^{\text {st }}$ and $24^{\text {th }}$ hours measurements of all groups. Considering these results, it was determined that the microhardness of the samples with storage in $37^{\circ} \mathrm{C}$ distilled water decreased. As known, approximately $75 \%$ of the polymerization takes place in the first 10 minutes after the initiation of light polymerization and continues after 24 hours (29). Many studies have shown that the dry storage of the composite resin samples can cause an increase in $\mathrm{SMH}$ values in time as an effect of continuous polymerization (30-32), however dry storage can not simulate the oral environment. The decrease in SMH in lower surface might be caused by water solubility of resin composites especially during the first 24 hours after curing $(33,34)$. Thereby, the third null hypothesis was rejected.

The SMH values of the present study can not be compared with literature because of the limited studies about hygienic sheaths. These studies focused on either the light output of LCU's or degree of conversion at the different thickness and none of them considered changes by the time $(7,12,14,26)$.

Chong et al. reported significant differences in light intensity output when different barriers were used. However, all their recorded values remained above the threshold (300 W/ $m^{2}$ ) required for adequate curing of the composite resins. Additionally, they considered a plastic glove and cellophane to be the best methods for prevention of contamination, as they allowed for the highest light intensity output (6).

According to the results of a study comparing the methods of various disposable barriers, transparent sheaths and cling film do not cause a significant change in the light power, while gloves and opaque barriers reduce light output by up to $71 \%$, leading to a decrease in polymerization efficiency (26).

Price et al. reported that the distance from the tip of the LCU to the composite resin had a much greater impact on the power density than the disposable barriers. They reported that a distance of $1 \mathrm{~mm}$ between the tip and the composite could cause a reduction in power density between $8 \%$ and $16 \%(35)$. Also, Aravamudhan et al. showed that the distance between the tip and the resin composite will influence the recorded degree of conversion (36). Therefore, to prevent the effects of the distance, all the samples were polymerized at the same distance. The minimum distance between the tip and the composite resin was ensured by using a plexiglass jig.

The sterility and correct use of sheaths should be considered during treatment. Avoiding contact of the sheath surroundings and being coated by resin adhesives which may influence polymerization before use are important. Often, the sheaths are not placed correctly on the tip and the air may be trapped in, which causes the light-curing tip to be more distant from the restoration and consequently decrease the curing efficiency.

Polymerization is one of the major concerns of restorative dentistry and can be affected by the thickness and type of composite material, infection control method and LCU. Therefore, further studies are needed to determine the relationship between the infection control methods and the polymerization efficiency of the LCU.

\section{CONCLUSION}

In the present study, it was observed that the plastic sheaths decreased the light output of the LCU's and caused a decrease in the SMH of the composite. Although the plastic sheaths were successful in infection control and preventing physical damage to the tips of the LCU's, they significantly reduced the polymerization efficiency.

\section{REFERENCES}

[1] Rode K, Kawano Y, Turbino M. Evaluation of curing light distance on resin composite microhardness and polymerization. Oper Dent. 2007; 32:571-578.

[2] David JR, Gomes OM, Gomes JC, Loguercio AD, Reis A. Effect of exposure time on curing efficiency of polymerizing units equipped with light-emitting diodes. J Oral Sci. 2007; 49:1924.

[3] Jeong T-S, Kang H-S, Kim S-K, Kim S, Kim H-I, Kwon YH. The effect of resin shades on microhardness, polymerization shrinkage, and color change of dental composite resins. Dent Mater J. 2009; 28:438-445.

[4] Yoon TH, Lee YK, Lim BS, Kim CW. Degree of polymerization of resin composites by different light sources. J Oral Rehabil. 2002; 29:1165-1173.

[5] Fan P, Schumacher RM, Azzolin K, Geary R, Eichmiller FC. Curing-light intensity and depth of cure of resin-based composites tested according to international standards. J Am Dent Assoc. 2002; 133:429-434.

[6] Chong S, Lam Y, Lee F, Ramalingam L, Yeo A, Lim C. Effect of various infection control methods for light-cure units on the cure of composite resins. Oper Dent. 1998; 23:150-154.

[7] Warren DP, Rice H, Powers J. Intensity of curing lights affected by barriers. J Dent Hyg. 2000; 74:20-23.

[8] Autio KL, Rosen S, Reynolds NJ, Bright JS. Studies on crosscontamination in the dental clinic. J Am Dent Assoc. 1980; 100:358-361.

[9] Caughman GB, Caughman WF, Napier N, Schuster G. Disinfection of visible-lightcuring devices. Oper Dent. 1989; 14:2-7. 
[10] Rueggeberg FA, Caughman WF, Comer RW. The effect of autoclaving on energy transmission through light-curing tips. J Am Dent Assoc. 1996; 127:1183-1187.

[11] Rueggeberg F, Caughman WF. Factors affecting light transmission of single-use, plastic light-curing tips. Oper Dent. 1998; 23:179-184.

[12] Scott BA, Felix CA, Price RB. Effect of disposable infection control barriers on light output from dental curing lights. J Can Dent Assoc. 2004; 70:105-110.

[13] Nelson SK, Caughman WF, Rueggeberg FA, Lockwood PE. Effect of glutaraldehyde cold sterilants on light transmission of curing tips. Quintessence Int. 1997; 28:725-730.

[14] Pollington S, Kahakachchi N, van Noort R. The influence of plastic light cure sheaths on the hardness of resin composite. Oper Dent. 2009; 34:741-745.

[15] Hodson NA, Dunne SM, Pankhurst CL. The effect of infectioncontrol barriers on the light intensity of light-cure units and depth of cure of composite. Prim Dent Care. 2005; 12:61-67.

[16] Kurachi C, Tuboy AM, Magalhães DV, Bagnato VS. Hardness evaluation of a dental composite polymerized with experimental LED-based devices. Dent Mater. 2001; 17:309315.

[17] Mandikos MN, McGivney GP, Davis E, Bush PJ, Carter JM. A comparison of the wear resistance and hardness of indirect composite resins. J Prosthet Dent. 2001; 85:386-395.

[18] Baharav H, Abraham D, Cardash H, Helft M. Effect of exposure time on the depth of polymerization of a visible light-cured composite resin. J Oral Rehabil. 1988; 15:167 - 172.

[19] Poskus LT, Placido E, Cardoso PEC. Influence of placement techniques on Vickers and Knoop hardness of class II composite resin restorations. Dent Mater. 2004; 20:726-732.

[20] Peutzfeldt A. Correlation between recordings obtained with a light-intensity tester and degree of conversion of a light-curing resin. Eur J Oral Sci. 1994; 102:73-75.

[21] Şakar-Deliormanli A, Güden M. Microhardness and fracture toughness of dental materials by indentation method. Journal of Biomedical Materials Research Part B: Applied Biomaterials: An Official Journal of The Society for Biomaterials, The Japanese Society for Biomaterials, The Australian Society for Biomaterials, The Korean Society for Biomaterials. 2006; 76:257-264.

[22] Rouhollahi M, Mohammadibasir M, Talim S. Comparative depth of cure among two light-cured core build-up composites by surface vickers hardness. J Dent. 2012; 9:255-261.

[23] Ülker HE, Yalçın M, Cebe F, Şengün A. Farklı Kompozit Materyallerinin İki Değişik Renginin Vickers Mikrosertliklerinin
Karşılaştııılması. Ondokuz Mayıs Üniversitesi Diş Hekimliği Fakültesi Dergisi. 2010; 11:92-96.

[24] Deb S, Sehmi H. A comparative study of the properties of dental resin composites polymerized with plasma and halogen light. Dent Mater. 2003; 19:517-522.

[25] Rueggeberg FA, Caughman WF, Chan DC. Novel approach to measure composite conversion kinetics during exposure with stepped or continuous light-curing. J Esthet Restor Dent. 1999; 11:197-205.

[26] McAndrew R, Lynch C, Pavli M, Bannon A, Milward P. The effect of disposable infection control barriers and physical damage on the power output of light curing units and light curing tips. Br Dent J. 2011; 210:E12.

[27] Saipullaev M, Erdemir U, Yildiz E. Influence of Bulk Thickness, Curing Time, and Curing Unit Type on the Microhardness of Different-Viscosity Bulk-Fill Composites. Mechanics of Composite Materials. 2018; 54:675-684.

[28] Bouschlicher M, Rueggeberg F, Wilson B. Correlation of bottom-to-top surface microhardness and conversion ratios for a variety of resin composite compositions. Oper Dent. 2004; 29:698-704.

[29] Andrzejewska E. Photopolymerization kinetics of multifunctional monomers. Prog Polym Sci. 2001; 26:605-665.

[30] Alshali RZ, Salim NA, Satterthwaite JD, Silikas N. Post-irradiation hardness development, chemical softening, and thermal stability of bulk-fill and conventional resin-composites. J Dent. 2015; 43:209-218.

[31] Mohamad D, Young R, Mann A, Watts D. Post-polymerization of dental resin composite evaluated with nanoindentation and micro-Raman spectroscopy. Archives of Orofacial Sciences 2007; 2:26-31

[32] Truffier-Boutry D, Demoustier-Champagne S, Devaux J, Biebuyck J-J, Mestdagh M, Larbanois P, et al. A physicochemical explanation of the post-polymerization shrinkage in dental resins. Dent Mater. 2006; 22:405-412.

[33] Watts D, Amer O, Combe E. Surface hardness development in light-cured composites. Dent Mater. 1987; 3:265-269.

[34] Øysæd H, Ruyter I. Water sorption and filler characteristics of composites for use in posterior teeth. J Dent Res. 1986; 65:1315-1318.

[35] Price RB, Derand T, Sedarous M, Andreou P, Loney RW. Effect of distance on the power density from two light guides. J Esthet Restor Dent. 2000; 12:320-327.

[36] Aravamudhan K, Rakowski D, Fan P. Variation of depth of cure and intensity with distance using LED curing lights. Dent Mater. 2006; 22:988-994. 